\title{
Report: \\ The University Health Clinic: Definition, educational practices and outcomes
}

\author{
K. Moore ${ }^{1}$, R. Bacon' 2 , T. Bevitt 2 , A. Bialocerkowski , N. Ciccone ${ }^{4}$, \\ N. Haworth ${ }^{5}$, L. Horstmanshof ${ }^{6}$, N. Milne', F. Naumann ${ }^{8}$, \\ B. Sanderson \& C. Wells ${ }^{3}$
}

\begin{abstract}
Introduction: Increasingly, universities are allocating substantial resources and efforts towards developing their own student-led clinical services (SLCS) within university health clinics (UHCs). For that reason, under the umbrella of the Australian and New Zealand Association for Health Professional Educators (ANZAPHE), clinical educationalists from 12 Australian universities have come together as a hot topic action group (HTAG) to collaboratively explore and enhance learning outcomes from this setting.
\end{abstract}

Context: SLCS within UHCs increase placement capacity to meet growing demand. Moreover, SLCS within UHCs have the potential to provide an outstanding learning opportunity through high-quality supervision and activities designed to develop clinical competencies. However, the benefits of providing clinical education experiences for health and medical students in this setting has not been formally assessed.

Typically, SLCS within UHCs are developed through consultation between universities and local health providers and are purposefully designed clinical placements with a focus on clinical educational activities for pre-registration students. UHCs may be located on or off campus and offer SLCS or other services to university staff, students and/or the wider

1 Moore Clinical Education Consultants and Researchers

2 University of Canberra

3 Griffith University

4 Edith Cowan University

5 Victoria University

6 Southern Cross University

7 Bond University

8 Queensland University of Technology

9 Curtin University

\section{Correspondence}

Dr Keri Moore

Moore Clinical Education Specialists and Researchers

PO Box 1460

Coolangatta, QLD 4225

Australia

Ph: +61 450465031

Email: mooreclinicaleducation@hotmail.com 
community. In SLCS, students' delivery of health services is supervised by university employed health professionals.

Scope: The work of the HTAG to date is presented in this paper, which defines the setting and outlines assumptions, aspirations, challenges and enablers. The next phase of work for the HTAG is to formally explore the educational value for health professional students' of SLCS delivered in UHCs and to develop resources and a quality assurance framework to guide the evaluation of these services.

Keywords: university clinics; student-led clinical services; clinical education.

\section{Introduction}

Increasingly, Australian universities are allocating substantial resources and efforts towards developing their own clinics - university health clinics (UHCs). At face value, UHCs provide valuable teaching and learning environments for university students, mainly, but not only, via student participation in student-led clinical services (SLCS). The experience of "hot topic action group" (HTAG) members who are involved in this setting indicates SLCS are offered as a means of operationalising the universities' tripartite mission of engagement with the community by offering a health service to the university and local community that provides opportunities for research and for students to participate in clinical experiential education. In doing so, SLCS in UHCs provide a vehicle for universities to demonstrate the axiom: University for the common good.

Examples of UHCs are seen internationally as well as in Australia. In the United States, student-run clinics provide services where healthcare is not traditionally funded, such as health services for homeless populations (Meah, Smith, \& Thomas, 2009; Palombaro, Dole, \& Lattanzi, 2011). Whereas the University of Calgary in Canada adopts the view that student-run clinics contribute to the faculty's mandates of re-education, service to society and social accountability (Campbell, Gibson, O’Neill, \& Thurston, 2013).

In Australia, SLCS provide opportunities for universities to service the community through programmes such as school health checks, indigenous health screening, staff health checks, rehabilitation for recovery from stroke, manual therapies and services for children with developmental delays. SLCS provide educational opportunities for students who are in various stages of their studies and involve students in both undergraduate and graduate entry master's programmes.

Under the umbrella of the Australian and New Zealand Association for Health Professional Educators (ANZAPHE), clinical educationalists from 12 Australian universities have come together as an HTAG to focus on exploring and improving clinical education within UHCs. Our aim is to grow the HTAG collaborative network to develop best practice frameworks and resources to contribute to the evidence base that supports clinical education in UHCs. Our objective is to explore the clinical educational procedures, practices and outcomes of UHCs to illuminate the extent to which student activities within UHCs support students' acquisition of the desired professional and employability competencies. 


\section{Context}

Among the HTAG, we share a view that in Australia, SLCS within UHCs help address placement shortages experienced in a number of health professions (Bacon, Williams, Grealish, \& Jamieson, 2015; Barnett et al., 2008; Burrows et al., 2013). It is felt that SLCS in UHCs can prepare health and medical students for, or compliment, clinical education undertaken at external placement sites.

Schuttle et al.'s (2015) systematic review of learning in student-run clinics in medicine reported high student satisfaction with learning but drew no conclusions about the extent of students' skill development, knowledge and behaviours. An earlier study in physiotherapy confirmed students can develop competencies through SLCS (Nicole, Fairbrother, Nagarajun, Blackford, \& McAllister, 2014). Another in dietetic clinical education confirmed that students can develop and demonstrate professional competencies within non-hospital placements (Bacon, Williams, \& Grealish, 2015).

SLCS within UHCs are not only thought to increase placement capacity to meet growing demand, they also provide an optimal environment that enables peer-learning and interprofessional education (Copley et al., 2007). SLCS within UHCs are well placed to exemplify best practice clinical learning environments, providing learning experiences that nurture students' development as capable, competent, independent thinkers and confident health professionals. Some SLCS provide a first introduction to clinical placements and preparation for later stage community-based placements, while others are the main clinical learning site for students during their studies at the specific institution. Yet, to date, we have limited evidence of the value of particular clinical education models, procedures and processes or the outcomes achieved through these unique clinics.

Typically, SLCS are set up with the primary aim of educating students in a supportive learning environment and, in some instances, to fill service gaps (Nicole et al., 2014). External businesses are required to either adopt a business model that returns a profit or they are publicly funded. Whereas, in the experience of the members of the HTAG, SLCS in UHCs are most often non-profit because the primary focus is to provide clinical placement education. Even so, the costs of administration, resources, insurances, space, equipment and governance need to be offset, as well as the costs of clinical educators who guide the students and provide feedback and/or assessment. Whether clinical training that occurs within a UHC costs more or less or is educationally superior or just as effective as external placements remains unknown. That said, many of the HTAG members are proactive in undertaking research in their own disciplines and contexts to explore these issues.

Discourse among HTAG members has clarified that, within our footprints, faculty appear to make two assumptions about clinical education in UHCs, neither of which are wellsupported by the available literature. Our first assumption is that the education provided in an Australian UHC, which may operate as a SLCS, is educationally effective, enhances personalised learning, is of a high and consistent standard and that opportunities to support "at risk" students are readily available. In this setting, the curriculum is organised to deliver a comprehensive clinical education experience, providing regular formative and 
summative assessments. Thus, poor student performance can be quickly identified and remedial educational activities scaffolded to support at-risk students' learning needs to bring them up to the required standards. Our second assumption is that Australian UHCs provide an ideal environment to support interprofessional training for health professional students, particularly when many clinics operate within faculties of health and have several professions training within the clinic. Yet, the extent and range of interprofessional SLCS operating within UHCs is unknown.

\section{Definitions}

UHCs are health clinics that fall under university governance and are developed in consultation between universities and local health providers. They are purposefully designed for clinical placements and aspire to a concurrent focus on education, healthcare, research and community service. UHCs are located either on or off campus. They offer SLCS and may also offer other services to university staff, students and/or the wider community. In SLCS, students' delivery of the health services is supervised by qualified health professionals who are contracted by the university. The business models of SLCS in UHCs vary and may include the financial imperative to be a viable business, or they may be non-profit entities subsidised by universities.

Guidelines for what defines SLCS in a UHC are not clear, and for this reason, the frame of reference the HTAG members have adopted has been informed by the Higher Education Standards Framework (Threshold Standards): Domains 1-6 (TEQSA, 2015) and the Guidance Note: Work-Integrated Learning (Version 1.2) (TEQSA, 2017).

SLCS can include models developed within existing services to overcome unmet service provision (Nicole et al., 2015). Supervisors do not carry their own caseload and focus on providing student support in a just-in-time manner, while at the same time, the students progressively move towards independence (Bostick, Hall, \& Miciak, 2014). SLCS provide the opportunity for students to improve their clinical reasoning skills, history taking skills and physical examination and interpretation skills (Campbell et al., 2013; Warner, Jelinek, \& Davidson, 2010).

There is a view that student-led clinical learning may offer pedagogical advantages similar to problem-based learning, although this has not been confirmed (Bostick et al., 2014). Copley et al. (2007) referenced Whitlam (1993) in suggesting that the two key theoretical elements underpinning the approach in student-run clinics are built on the notion of cognitive constructivism - the promotion of student independence and active learning.

In clinical placements hosted within existing health services, the focus of activities is on providing clinical services, with student learning needs managed within the context of existing time and resource constraints. In comparison, according to recent authors, SLCS can be considered learner-centred, because all clients understand and are respectful of students' need to learn (Barrow \& McKimm, 2010; Bostick et al., 2014). Students perceive SLCS to be safe places to learn, and they have a sense of ownership and responsibility (Bostick et al., 2014; Kavanagh, Kearns, \& McGarry, 2015). A report on dietetic students learning interview skills in a UHC at the University of the 
Sunshine Coast claimed students were able to discover the nuances of practice and develop people skills and confidence (Swanepoel, Tweedie, \& Maher, 2016).

Table 1 (below) is a snapshot of the scale of SLCS in UHCs within the geographical footprint of the authors of this paper.

Table 1

A Snapshot of Some Student-Led Clinical Services in University Health Clinics in Australia

\begin{tabular}{l|l|l} 
University & $\begin{array}{l}\text { Student-Led Clinical Services in University } \\
\text { Health Clinics }\end{array}$ & Location of Clinics \\
\hline Bond University & $\begin{array}{l}\text { Physiotherapy, psychology, exercise and sports science, } \\
\text { nutrition, dietetics }\end{array}$ & $\begin{array}{l}\text { Robina, OLD } \\
\text { (on campus) }\end{array}$ \\
\hline Curtin University & $\begin{array}{l}\text { Physiotherapy, occupational therapy, speech pathology, } \\
\text { exercise \& sports science, nursing, professional } \\
\text { psychology, counselling psychology, social work, } \\
\text { pharmacy, dietetics }\end{array}$ & Perth, WA \\
\hline Edith Cowan & $\begin{array}{l}\text { Dietetics, exercise \& sports science, exercise physiology, } \\
\text { psychology, occupational therapy, speech pathology }\end{array}$ & $\begin{array}{l}\text { Perth, WA } \\
\text { (on campus) }\end{array}$ \\
\hline Griffith University & $\begin{array}{l}\text { Dentistry, dietetics, exercise physiology, physiotherapy, } \\
\text { psychology, speech pathology }\end{array}$ & Gold Coast, OLD \\
\hline $\begin{array}{l}\text { Oueensland University } \\
\text { of Technology }\end{array}$ & $\begin{array}{l}\text { Exercise physiology, nutrition, dietetics, podiatry, } \\
\text { optometry, psychology, counselling, social work, nursing }\end{array}$ & $\begin{array}{l}\text { Kelvin Grove, } \\
\text { Brisbane, OLD } \\
\text { (on campus) }\end{array}$ \\
\hline $\begin{array}{l}\text { Southern Cross } \\
\text { University }\end{array}$ & $\begin{array}{l}\text { Occupational therapy, speech pathology, clinical } \\
\text { exercise physiology, podiatry, pedorthics, osteopathy } \\
\text { (other health professions in the school that do not offer } \\
\text { student-led clinics: nursing and midwifery) }\end{array}$ & $\begin{array}{l}\text { Lismore, NSW; } \\
\text { Coolangatta, OLD }\end{array}$ \\
\hline University of Canberra & $\begin{array}{l}\text { Musculoskeletal physiotherapy, neurological and falls } \\
\text { physiotherapy, exercise physiology, nutrition and } \\
\text { dietetics, occupational therapy, psychology, counselling }\end{array}$ & $\begin{array}{l}\text { Bruce, ACT } \\
\text { (on campus) }\end{array}$ \\
\hline Osteopathy, nutritional therapy, dermal sciences, \\
psychology, social work
\end{tabular}




\section{Benefits}

The educational and health services provided by students through Australian UHCs, whether on or off campus, are generally planned in collaboration with local communities. They are mostly in urban locations but sometimes provide healthcare in underserviced areas through rural and remote clinics (Allan, O’Meara, Pope, Higgs, \& Kent, 2011). SLCS in UHCs can assist in addressing placement or workforce shortages in underserviced areas and, through this, can demonstrate the value of the profession to the community (Bacon, Williams, Grealish, et al., 2015). We suggest several benefits of SLCS in UHCs:

\section{1) Junior students}

Students can have early exposure, in the curriculum, to the profession and start forming a professional identity and begin thinking like a professional. Learning activities, if so designed, may better assist students to establish their own identity, to set career expectations and to identify what is required in the latter years of their courses. These opportunities connect students earlier in the course to the relevance of their learning, which in turn encourages them to set more future-focused goals that can enhance success.

\section{2) Senior students}

SLCS in UHCs are important for senior students because in typical educational activities, students (under the supervision of registered health professionals) are accountable for their contribution to health service delivery. Similarly, in relation to clinic operations in medicine, Sheu, O'Brien, O'Sullivan, Kwong and Lai's (2013) study demonstrated that student-run clinics provide students with an appreciation of the overall function of health clinics and their complexity, limited resources and context within the wider healthcare system.

\section{3) Interprofessional learning}

In UHCs, students often work in collaboration with students from other health professions, for example: the student-led interprofessional clinic in primary care (teambased diabetes care) Monash University (Kent \& Keating, 2013); Curtin University's team-based interprofessional practice programme (Brewer \& Barr, 2016); and the University of Queensland's clinic that hosts occupational therapy, speech pathology and music therapy services (Copley et al., 2007).

\section{4) Clinical educators}

SLCS provide an opportunity to implement and evaluate new models of service and/or models of supervision that are informed by evidence-based research (Allan et al., 2011; Bacon, Williams, Grealish, et al., 2015; Burrows et al., 2013). The university can directly select staff who are both high-quality educators and clinicians. UHCs can provide an incubator for new graduates and alumni wanting to begin a teaching career and can also provide an avenue for full-time academics to maintain clinical currency. UHCs can and do attract experienced practitioners who do not want to engage in full academic life and those without formal research backgrounds who, nevertheless, have substantial clinical knowledge and skill to contribute to the delivery of the clinical curriculum. 


\section{Challenges}

Although there are many benefits of UHCs, there are clear challenges to this type of clinical education. A seminal paper in 2008 identified and published the challenges for outpatient clinics in general (Ramani \& Leinster, 2008), and these are similar in nature to the SLCS offered within Australian UHCs. The challenges of outpatient clinics identified by Ramani and Leinster (2008) are listed below (Figure 1).

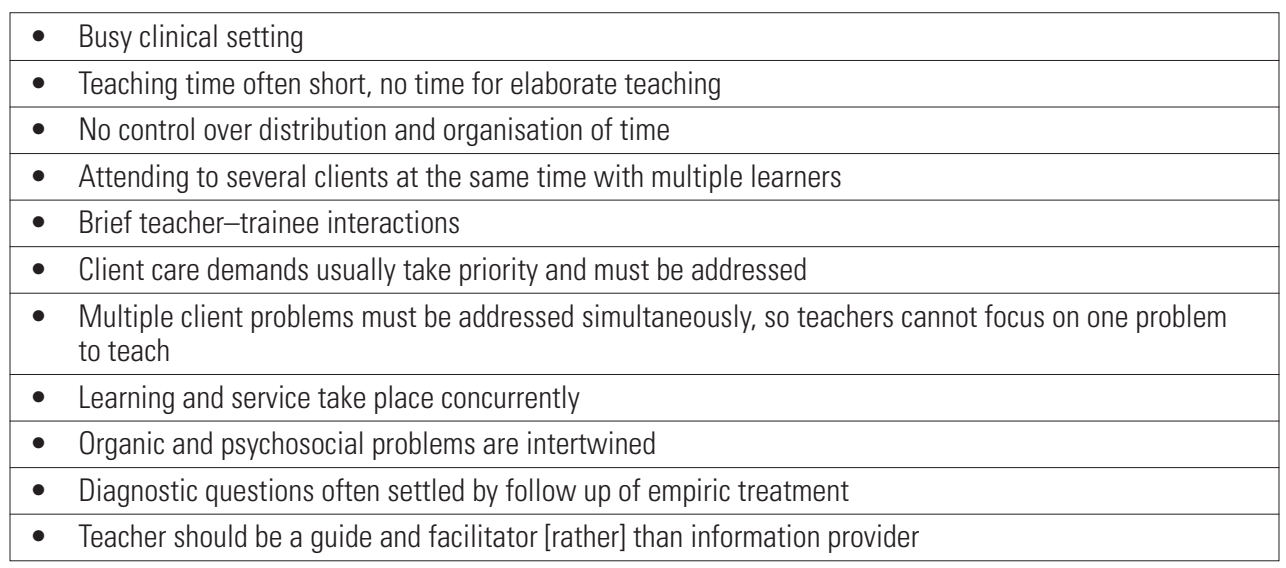

Figure 1.

Challenges of outpatient teaching (Ramani \& Leinster, 2008).

Other challenges of SLCS in UHCs, which we have identified, are:

\section{1) Student availability}

A key challenge to organising SLCS in UHCs is managing clinical operations in conjunction with the academic timetable. For example, students are not always available to be rostered to clinic during examination periods and semester breaks, and research has identified that student unavailability to sustain the SLCS offering may affect the continuity of client care over the calendar year (Campbell et al., 2013; Kavanagh et al., 2015). If the clinical placements are organised in block mode, for example, two 6-week blocks per year, it can be difficult for SLCS to build and maintain client numbers, provide continuity of care and provide optimal care for clients. SLCS work best if students are organised to attend longitudinal placements, for instance, one afternoon a week for the semester.

2) Clinical educator availability

Similar to the above, sourcing, training and retaining clinical educators to supervise student clinical placements across the full calendar year can be challenging, as can having adequate clinical space and equipment (Bostick et al., 2014; Kavanagh et al., 2015; Smith et al., 2014). 
3) Costs

The financial arrangements for clients in SLCS mean students are not orientated to different funding models for professional health service delivery (e.g., private insurance). UHCs typically rely on clients who are prepared to self-fund treatments because some third-party bodies do not refund the cost of health services provided by students (e.g., Australian Department of Veteran Affairs, Motor Vehicle Accident, Workers Compensation, Medicare and private health insurance companies). The good news is that clients without private health or other insurance are provided a low-cost service option.

Another consequence of the low fee for SLCS is that a low fee-for-service (or no fee-for-service) may create different client expectations, be they positive or negative, about the effectiveness and efficiency of student-led treatment. Experience tells us that within private practice settings, where clients pay full fees, expectations can be higher, and if clients are not satisfied with the value for money offered, they will go elsewhere. This may teach students, who typically practise in private settings in the future, about organising and managing a viable business. Furthermore, feedback from clients to students during SLCS has been identified as overly positive rather than objective (Burrows et al., 2013; Moore, 2012), and this can potentially lead to students developing a false sense of their clinical skill and capabilities.

\section{4) University-community relationships}

Tensions have been known to develop between universities and local healthcare providers who regard SLCS as unfair competition because of the low fee for service. In some situations, this has lessened the pool of available clinical educators from the local area (because health professionals don't want to be associated with and support the enterprise and business model) and the external clinical placements offered by health professionals in the local area.

\section{5) Financial sustainability}

The elements that make up the cost of running a health service are generally understood, and when the service is provided by students and qualified health professionals, the cost of clinical educators and the associated education resources needs to be factored in. Any cost-benefit analysis needs to consider the likelihood of longer consultation times and additional costs related to evaluation and assessment of students' performance, as well as time for discussion, tutorials and feedback. The fiscal tensions and competing priorities between costs for the supply of clinical services and income and the costs of resourcing student learning experiences has been discussed by others (Haines, Isles, Jones, \& Jull, 2011), but not in relation to SLCS in UHCs. 


\section{Essential elements of quality SLCS in UHCs}

The now disestablished Health Workforce Australia published a report on the elements of quality in clinical placements (Siggins Miller Consultants, 2012). This information, together with the considered opinions of the HTAG members, suggests that the essential elements of success are prior preparation and planning and three key enablers for delivering effective and efficient SLCS in UHCs: consideration of resource implications, universitycommunity partnership and collaboration and support from all stakeholders.

\section{Consideration of resource implications}

Consideration needs to be given to training staff to be high-quality clinical educators, financial or in-kind contributions, if required, to set up the environment for student presence, the necessity of a sustained commitment to the clinic by the university and access. The university commitment includes:

- a university professional clinical educator or interprofessional facilitator as a supernumerary position to academic appointments within a programme

- a dedicated academic leader within the university who can bridge the gap between coursework and clinical learning and act as a champion for clinical education (CE)/ interprofessional learning models in authentic practice environments

- time for the design, implementation and evaluation processes, including the development of a theoretical practice and learning framework that guides the dayto-day activities of the UHC, so that best- and evidence-based practices are being implemented and continually evaluated using quantitative and qualitative methods.

Access for UHC students to physical resources to facilitate learning (i.e., space, tables, chairs, whiteboards, lockers, internet access, etc.), for UHC clinical staff to professional development funding as per other academic staff and for UHC organisers to university marketing initiatives that align with the professional advertising standards of the associated health professions are all considerations.

\section{University-community partnership}

Commitment both from bottom up and top down within the organisations involved is critical, especially if the clinic engages external partners to run the clinic or provide the service to the community. Stakeholders need to work together to ensure the relationship is mutually beneficial and realises the universities strategic plan and policies. All partner organisations of the UHC should commit to:

- a formal legal agreement with the university regarding clinical education priorities, practices and responsibilities of all parties

- continuous quality improvement that is aligned to the relevant health professional standards and the university quality cycle (i.e., TEQSA) to enhance outcomes and minimise risk to all stakeholders 
- the development of a financial model (e.g., low fee-for-service model) with appropriate referral pathways for clients.

\section{Collaboration and support from all stakebolders}

Collaboration needs to be sought with a variety of university stakeholders through standard items on appropriate committee agendas. These include:

- the development of a university-community engagement plan to facilitate the participation of key stakeholders through use of a defined model for stakeholder engagement. The International Association of Public Participation (2016) mapped the engagement strategies as: informing, consulting, involving, collaborating and empowering.

- course accreditation, i.e., involvement of relevant health professional programme accrediting bodies and university clinical staff so that the UHC targets gaps in placement availability

- outreach clinical services, including consideration of UHC services being embedded in non-traditional environments (e.g., schools or aged-care facilities) so that additional funding partners can be considered (i.e., government, non-government organisations and philanthropic bodies)

- Timetabling, so that client care can be provided by student-led services year-round, which may mean working with other universities.

\section{Future activities of the HTAG}

Notwithstanding the many challenges of organising and managing a SLCS in a UHCs, they have the potential to realise university aspirations to work with industry and community to offer quality clinical education experiences that ensure health graduates are fit for purpose to provide high-quality healthcare services to communities.

Going forward, the next activities of the HTAG are to develop a quality assurance framework (QAF). This will include strategies for answering previously unanswered questions, such as, but not limited to, a cost-benefit analysis, a study of interprofessional clinical education models and an exploration of what students regard as the benefits of an education through this unique educational setting. Our findings will potentially contribute to debate regarding a nationally-consistent approach to the funding and management of UHCs through clinical training funds, with consideration being given to allocating a protected component of clinical placement costs.

\section{Conclusion}

Little about the benefits of providing health professional student clinical education through SLCS in UHCs has been formally assessed previously. The HTAG members have defined the setting and outlined the aspirations, challenges and enablers. Future work of this HTAG group will include developing resources and identifying a quality assurance framework (QAF). This framework will include strategies to confirm or deny 
our assumptions that, within the Australian setting, the education provided is effective, enhances personalised learning, is of high-quality, provides mechanisms for the early detection of and effective interventions for "at risk" students and that UHCs provide an ideal environment to support interprofessional training. Also included in the QAF will be strategies to identify: costs and benefits, the educational value of different clinical education models and an evaluation framework for identifying stakeholder's views of the benefits, challenges and enablers of an education through this unique health education setting. We now look to our Australian and international colleagues for their contribution, assistance and comment.

\section{Acknowledgements}

The authors would like to acknowledge the sage contributions of Jane Conway (University of New England) and Dr Sanjyot Yogholkar (Macquarie University) to the discussion of ideas presented in this paper.

\section{References}

Allan, J., O’Meara, P., Pope, R., Higgs, J., \& Kent, J. (2011). The role of context in establishing university clinics. Health \& Social Care in the Community, 19(2), 217-224.

Australian Tertiary Education Quality and Standards Agency (TEQSA). (2015). Higher education standards framework (Threshold standards). Retrieved from https:// www.legislation.gov.au/Details/F2015L01639

Australian Tertiary Education Quality and Standards Agency (TEQSA). (2017). Guidance note: Work-integrated learning (Version 1.2). Retrieved 20 October 2017, from https://www.teqsa.gov.au/latest-news/publications/guidance-note-workintegrated-learning

Bacon, R., Williams, L., \& Grealish, L. (2015). Aged care facilities and primary health-care clinics provide appropriate settings for dietetic students to demonstrate individual case management clinical competence. Nutrition and Dietetics, 72(1), 54-62. doi:10.1111/1747-0080.12156

Bacon, R., Williams, L., Grealish, L., \& Jamieson, M. (2015). Student-assisted services (SAS): An innovative clinical education model that prepares graduates for the future, contributes to health service delivery, and addresses internship shortages. Journal of the Academy of Nutrition and Dietetics, 115(3), 351-352.

Barnett, T., Cross, M., Jacob, E., Shahwan-Akl, L., Welch, A., Caldwell, A., \& Berry, R. (2008). Building capacity for the clinical placement of nursing students. Collegian, 15(2), 55-61.

Barrow, M., \& McKimm, J. (2010). Assuring and maintaining quality in clinical education. British Journal of Hospital Medicine, 71(4), 224-228.

Bostick, G., Hall, M., \& Miciak, M. (2014). Novel clinical learning from a studentled clinic. The Clinical Teacher, 11(7), 512-515. 
Brewer, M. L., \& Barr, H. (2016). Interprofessional education and practice guide No. 8: Team-based interprofessional practice placements. Journal of Interprofessional Care, 30(6), 747-753.

Burrows, T., Patterson, A., Bacon, A., Mitchell, L., Wicks, L., Baines, S., \& Williams, L. T. (2013). Client satisfaction and weight loss outcomes of student centred dietetic outpatient clinics. Obesity Research \& Clinical Practice, 7(5), e421-e430.

Campbell, D. J., Gibson, K., O’Neill, B. G., \& Thurston, W. E. (2013). The role of a student-run clinic in providing primary care for Calgary's homeless populations: A qualitative study. BMC Health Services Research, 13(1), 277.

Copley, J. A., Allison, H. D., Hill, A. E., Moran, M. C., Tait, J. A., \& Day, T. (2007). Making interprofessional education real: A university clinic model. Australian Health Review, 31(3), 351-357.

Haines, T., Isles, R., Jones, A., \& Jull, G. (2011). Economic consequences in clinical education. Focus on Health Professional Education: A Multi-disciplinary Journal, 12(3), 53.

International Association of Public Participation (IAP2). (2016). Public participation spectrum and core values. Retrieved from http://www.iap2.org.au/resourcebank

Kavanagh, J., Kearns, A., \& McGarry, T. (2015). The benefits and challenges of student-led clinics within an Irish context. The Journal of Practice Teaching and Learning, 13(2-3), 58-72.

Kent, F., \& Keating, J. (2013). Patient outcomes from a student-led interprofessional clinic in primary care. Journal of Interprofessional Care, 27(4), 336-338.

Meah, Y. S., Smith, E. L., \& Thomas, D. C. (2009). Student-run health clinic: Novel arena to educate medical students on systems-based practice. Mount Sinai Journal of Medicine: A Journal of Translational and Personalized Medicine, 76(4), 344-356.

Moore, K. (2012). Professional placement educational processes: Balancing studentcentred education and client-centred care during clinical education. Journal of Cooperative Education and Internships, 45(2), 37-48.

Nicole, M., Fairbrother, M., Nagarajan, S. V., Blackford, J., Sheepway, L., Penman, M., \& McAllister, L. (2015). Student-led services in a hospital aged care temporary stay unit: Sustaining student placement capacity and physiotherapy service provisions. Asia-Pacific Journal of Cooperative Education, 16(4), 327-342.

Nicole, M., Fairbrother, M., Nagarajun, S. V., Blackford, J., \& McAllister, L. (2014). Student-led clinics: Building placement capacity and filling service gap. Paper presented at the Australian Collaborative Education Network, Gold Coast, Australia.

Palombaro, M., Dole, R., \& Lattanzi, J. (2011). A case report of a student-led pro bono clinic: A proposed model for meeting student and community needs in a sustainable manner. Physical Therapy, 91(11), 1627.

Ramani, S., \& Leinster, S. (2008). AMEE guide no. 34: Teaching in the clinical environment. Medical Teacher, 30(4), 347-364. 
Schutte, T., Tichelaar, J., Dekker, R. S., Agtmael, M. A., Vries, T. P., \& Richir, M. C. (2015). Learning in student-run clinics: A systematic review. Medical Education, 49(3), 249-263.

Sheu, L., O’Brien, B., O’Sullivan, P. S., Kwong, A., \& Lai, C. J. (2013). Systemsbased practice learning opportunities in student-run clinics: A qualitative analysis of student experiences. Academic Medicine, 88(6), 831-836.

Siggins Miller Consultants. (2012). Promoting quality in clinical placements: Literature review and national stakeholder consultation. Health Workforce Australia. Retrieved from file://C:/Users/Keri\%20Marie/AppData/Local/Microsoft/ Windows/INetCache/IE/8HSTTCD0/Promoting-quality-in-clinical-placementsreport-20130408.pdf

Smith, S., Thomas, R., Cruz, M., Griggs, R., Moscato, B., \& Ferrara, A. (2014). Presence and characteristics of student-run free clinics in medical schools. JAMA, 312(22), 2407-2410.

Swanepoel, E., Tweedie, J., \& Maher, J. (2016). Building dietetic student confidence and professional identity through participation in a university health clinic. Nutrition \& Dietetics, 73(3), 229-234.

Warner, P., Jelinek, H., \& Davidson, P. M. (2010). A university clinic: An innovative model for improving clinical practice. Australian Journal of Advanced Nursing, $27(4), 38$.

Whitman, N. (1993). A review of constructivism: Understanding and using a relatively new theory. Family Medicine, 25(8), 517-521. 